\title{
Indigenous children's language: Acquisition, preservation and evolution of language in minority contexts
}

First Language 2015, Vol. 35(4-5) 279-285 (C) The Author(s) 2015

Reprints and permissions: sagepub.co.uk/journalsPermissions.nav DOI: $10.1|77 / 0| 427237|56| 8056$ fla.sagepub.com

@SAGE

\section{Barbara F. Kelly}

The University of Melbourne, Australia.

\section{Evan Kidd}

The Australian National University, Australia; The ARC Centre of Excellence for the Dynamics of Language, Australia

\section{Gillian Wigglesworth}

The University of Melbourne, Australia; The ARC Centre of Excellence for the Dynamics of Language, Australia

A comprehensive theory of language acquisition must explain how human infants can learn any one of the world's 7000 or so languages. As such, an important part of understanding how languages are learned is to investigate acquisition across a range of diverse languages and sociocultural contexts. To this end, cross-linguistic and cross-cultural language research has been pervasive in the field of first language acquisition since the early 1980s. In groundbreaking work, Slobin (1985) noted that the study of acquisition in cross-linguistic perspective can be used to reveal both developmental universals and language-specific acquisition patterns. Since this observation there have been several waves of cross-linguistic first language acquisition research, and more recently we have seen a rise in research investigating lesser-known languages. This special issue brings together work on several such languages, spoken in minority contexts. It is the first collection of language development research dedicated to the acquisition of under-studied or little-known languages and by extension, different cultures.

\section{Corresponding author:}

Barbara F. Kelly, School of Languages and Linguistics, The University of Melbourne, Parkville, VIC 30I0,

Australia.

Email: b.kelly@unimelb.edu.au 
Why lesser-known languages, and why minority contexts? First and foremost, acquisition theories need data from different languages, language families and cultural groups across the broadest typological array possible, and yet many theories of acquisition have been developed through analyses of English and other major world languages. Thus they are likely to be skewed by sampling bias.

Languages of European origin constitute a small percentage of the total number of languages spoken worldwide. The Ethnologue (2015) lists 7102 languages spoken across the world. Of these, only 286 languages are languages of European origin, a mere 4\% of the total number of languages spoken across the planet, and representing approximately only $26 \%$ of the total number of language speakers alive today. Compare this to the languages of the Pacific. The Ethnologue lists 1313 languages spoken in the Pacific, constituting $18.5 \%$ of the world's languages. Of these, very few have been described, and even fewer have child language data available.

Lieven and Stoll (2010) note that only around 70-80 languages have been the focus of acquisition studies (around 1\% of the world's languages). This somewhat alarming statistic suggests that the time is now ripe for researchers working on lesser-known languages to contribute to the field's knowledge about how children learn a range of very different languages across differing cultures, and in doing so, for this research to make a contribution to language acquisition theory.

The potential benefits are many. First, decades of descriptive work in linguistic typology have culminated in strong challenges to the existence of a Universal Grammar (Evans \& Levinson, 2009), a long-held axiom of formal language acquisition theory. To be sure, cross-linguistic work in acquisition has long fuelled this debate (e.g. MacWhinney \& Bates, 1989), but only as we collect a greater number of data points will we move closer toward a better understanding of the initial state of the human capacity for language and the types of social and cultural contexts in which language is successfully transmitted. A focus on linguistic diversity enables the investigation and postulation of universals in language acquisition, if and in whatever form they exist. In doing so, we can determine the sorts of things that are evident in child-directed speech, in children's language production and in adult language, teasing out the threads at the intersection of language, culture and cognition. The study and dissemination of research into lesser-known, under-described languages with small communities significantly contributes to this aim because it not only reflects the diversity of languages present in the world, but provides a better representation of the social and economic conditions under which the majority of the world's population acquire language (Heinrich, Heins, \& Norenzayan, 2010).

Related to this point, the study of smaller languages has taken on intense urgency in the past few decades due to the rapid extinction of these languages (Evans, 2010). The Language Documentation movement has toiled tirelessly in the pursuit of documenting languages before they disappear, an effort to which child language researchers have much to offer. Many children acquire smaller and minority languages in rich multilingual environments, where the influence of dominant languages affects acquisition (e.g., Stoll, Zakharko, Moran, Schikowski, \& Bickel, 2015). Understanding the acquisition process where systems compete and may be in flux due to language contact, while no small task, will help us understand the social and economic conditions which favour successful preservation of minority languages, which could ultimately equip communities with the tools to stem the flow of language loss. 
With these points in mind we now turn to the articles in this special issue.

\section{Overview of articles}

In their article, Kelly, Forshaw, Nordlinger, and Wigglesworth (2015) review first language acquisition research in traditional, non-industrialised contexts. They focus on the challenges remote fieldwork contexts pose for researchers given received best practice in the field, which has been largely shaped without the restrictions of remote fieldwork in mind. They begin by briefly reviewing notable child language research projects that have been conducted on typologically diverse languages. On reflection, we should not underestimate the large impact many of these projects have had on the field (many summarised in Slobin, 1985-1997), with each unique data point allowing us to test theories that have been built upon data heavily biased by European languages. Kelly et al. juxtapose best practice in first language acquisition research against the many challenges of fieldwork, demonstrating that even basic research procedures (e.g. ethics, consent, recruitment and data collection) differ considerably from familiar laboratory-based research. By way of illustration, they outline their own experience of walking the fine line between optimality and practicality in the field, describing a range of issues they have faced in their Language Acquisition in Murrinhpatha (LAMP) project. The project is collecting a naturalistic corpus of child language data from children acquiring Murrinhpatha, an Indigenous language spoken in northern Australia. Along with similar successful projects (e.g. Allen \& Crago, 1996; Bavin, 1992; Demuth, 1992; Lieven \& Stoll, 2013), the insights afforded by experienced field researchers will hopefully stimulate similar projects during the current era of rapid worldwide language loss.

Staying on the Australian continent, O'Shannessy (2015) describes work conducted in the unique field context of Lajamanu. Although small in population (approx. 600 people), Lajamanu is similar to many field contexts involving small languages in that its population is highly multilingual (e.g. as in places such as Papua New Guinea or Vanuatu). The multilingualism in Lajamanu is unique because recent historical events have led to the creation of a new mixed language. Traditionally its people spoke Warlpiri as a first language, and for some time have had contact with varieties of English and Australian Aboriginal Kriol. In the last generation or so the complex multilingual situation led to the development of Light Warlpiri, which integrates many different features from the other languages spoken in the community. Because Warlpiri and Light Warlpiri have considerable lexical and morphosyntactic overlap, the linguistic context could potentially be confusing to the child language learner, who must learn a range of different forms and social contexts in which the use of either language is conventional in the community. In her article, O'Shannessy considers whether and how children and adults in the community differentiate between Warlpiri and Light Warlpiri forms. Focusing on lexical and morphological choice in instances of variation, she shows that children differentiate between the two languages, and in some cases take this differentiation further than adult speakers. Invoking a 'community of practice' model (e.g. Bucholtz, 1999; Eckert, 1989), O'Shannessy takes this differentiation to reflect the children's sociolinguistic identities as competent multilingual members of their community.

In the next article, Lebon-Eyquem (2015) covers similar ground, exploring the sociolinguistic landscape shaping the acquisition of Reunion Island Creole. The language is 
spoken on Reunion Island alongside its lexifier language French. The two languages were traditionally spoken in different cultural spaces (French in formal settings, Creole in social settings). However, as Lebon-Eyquem notes, they are, to varying degrees among individuals, used interchangeably within utterances, resulting in an intermediate interlectal variety. Her article considers the use of such mixed utterances in 110 5-year-old children on Reunion Island, exploring the dominance profiles of the children and how they relate to some prominent sociolinguistic variables (gender, socioeconomic status). Such studies of diglossia are important in child language: as Lebon-Eyquem shows, the majority of the children in her study are dominant in Creole. Such knowledge is important in the contexts of education and language assessment, since the unique sociolinguistic situation of Reunion Island means that children growing up on the island will have qualitatively different acquisition patterns to monolingual children growing up in mainland France.

In the next article, Vogt, Schots, and Mastin (2015) report on a cross-cultural investigation of child-directed speech (CDS), comparing CDS to Dutch-learning infants in The Netherlands with CDS to Changana-learning and bilingual Changana/Portugeuselearning in urban and rural communities in Mozambique. They link cross-cultural differences in the functions of CDS to fundamental cultural differences concerning the role of the individuals in society (Greenfield, 2009). Specifically, their groups map onto Keller's (2012) three sociocultural learning environments: (1) Western post-industrialised, information-based (The Netherlands), (2) agrarian, subsistence-based environments (rural Mozambique) and (3) a hybrid version of (1) and (2) (urban Mozambique). They found that, consistent with past cross-cultural comparisons, Dutch CDS contained comparatively more utterances denoting a cognitive intention than did CDS in Mozambique, consistent with the Western emphasis on individual psychological autonomy. In contrast, Mozambique CDS contained significantly greater amounts of imperatives, consistent with an emphasis in many non-Western cultures on action autonomy. CDS across all cultures contained fairly equivalent amounts of utterances containing socioemotional intentions (although these were slightly higher in urban Mozambique), suggesting that fostering interpersonal relations and socioemotional bonding may be relatively stable across the three contexts.

In their article on teleological talk in parent-child conversations in Quechua, Gelman, Mannheim, Escalante, and Sanchez Tapia (2015) demonstrate how working with indigenous languages in traditional contexts can illuminate debates concerning conceptual development. They test the predictions of two current theories regarding the nature of teleological concepts in development: (1) Selective Teleology, which argues that children and adults only take a teleological stance to biological properties (e.g. a giraffe's neck is for reaching leaves on tall trees) and artefacts (e.g. a chair is for sitting on), and (2) Promiscuous Teleology, which argues that humans have a broad, naive tendency to apply teleological explanations across their range of experience (e.g. mountains are tall for people to climb). Quechua, a highly agglutinative language, contains a nominal suffix - paq, which expresses teleology. Thus, teleology is grammaticalised. Children were recorded talking about a range of concepts with their parents, and both children's and parents' utterances were coded for teleological status. The results suggested that teleological talk in Quechua increases with children's age, and is unevenly applied across different conceptual domains. The results 
were therefore not consistent with either Selective or Promiscuous Teleology, but instead suggest that teleological language might vary according to culturally specific knowledge systems and beliefs. The study highlights the important of cross-cultural research in developmental psychology, underlining the importance of theory testing outside of familiar Western laboratory contexts.

The final two articles in the special issue deal with issues regarding language assessment. Allen and Dench (2015) explore the most accurate and efficient way to calculate mean length of utterance (MLU) in Eastern Canadian Inuktitut. While we know a lot about the acquisition of Inuktitut, there is a critical lack of tools that can be used to measure language ability and difficulties. For a language like Inuktitut, calculating MLU in morphemes (MLUm) is an obvious choice because the language is polysynthetic and agglutinative, containing rich verbal and nominal morphology. However, as the authors note, calculating MLUm in Inuktitut poses a number of theoretical and practical challenges; for instance, as in other languages, the productivity of a morpheme is difficult to establish, and their identification requires specialist linguistic knowledge that a clinician may not necessarily possess. Across three studies with diverse populations (pre-schoolers, older children and adults, one 5-year-old with Specific Language Impairment), Allen and Dench take MLUm as a benchmark and compare it to five measures of MLU and mean length of word (MLW), as well as five measures of the longest utterance/word. They conclude that MLU in syllables provides the best balance between reliably assessing language level and ease of calculation, while at the same time suiting Inuktitut structure.

In the final article, Reese et al. (2015) report on the development of short form MacArthur-Bates Communicative Development Inventories (MB-CDI) for Samoanand Tongan-speaking children growing up in New Zealand. While the majority language in New Zealand is English and the local indigenous language is Maori, there are significant numbers of Pacific Island communities in the country, who speak a range of Polynesian languages. Additionally, there are large cultural differences in childrearing practices between Western and Polynesian cultures (e.g. Ochs, 1982), making normative data essential to tracking children's development. To this end, Reese et al. have developed an important tool for measuring Samoan- and Tongan-speaking children's early language development, providing a best practice model for others developing similar tools for speakers of minority languages in countries around the world.

\section{Conclusion}

The articles presented here reflect an emphasis on lesser-known, typologically diverse language development. A broad range of languages is represented and the articles contribute to one or both of the original aims of this special issue. The first is to shed some light on underdescribed languages. The second is to highlight the ways in which different approaches to FLA research can yield valuable results, contributing to our understanding of the interplay between global linguistic features and local language-learning environments. The research presented in the following pages heralds the potential for new opportunities of analysing and presenting data from lesser-known languages and data collected in fieldwork situations. 


\section{Acknowledgements}

We thank all authors and reviewers who have contributed to this special issue, and Kevin Durkin for his support for the project.

\section{Funding}

Kelly and Wigglesworth's time on this project was supported by the Australian Research Council grant DP110100961, and Kidd's and Wigglesworth's time was supported by the Australian Research Council grant CE140100041.

\section{References}

Allen, S., \& Crago, M. (1996). Early passive acquisition in Inuktitut. Journal of Child Language, 23, 129-156.

Allen, S., \& Dench, C. (2015). Calculating mean length of utterance for Eastern Canadian Inuktitut. First Language, 35, 377-406.

Bavin, E. L. (1992). The acquisition of Warlpiri. In D. I. Slobin (Ed.), The crosslinguistic study of language acquisition (Vol. 3, pp. 309-371). Hillsdale, NJ: Lawrence Erlbaum.

Bucholtz, M. (1999). 'Why be normal?': Language and identity practices in a community of nerd girls. Language in Society, 28, 203-223.

Demuth, K. (1992). Acquisition of Sesotho. In D. I. Slobin (Ed.), The crosslinguistic study of language acquisition (Vol. 3, pp. 557-638). Hillsdale, NJ: Lawrence Erlbaum.

Eckert, P. (1989). Jocks and burnouts: Social categories and identity in the high school. New York, NY: Teachers College Press.

The Ethnologue. (2015). Retrieved from https://www.ethnologue.com/about

Evans, N., \& Levinson, S. (2009). The myth of language universals: Language diversity and its importance for cognitive science. Behavioral \& Brain Sciences, 32, 429-448.

Evans, N. (2010). Dying words: Endangered languages and what they have to tell us. WileyBlackwell, Chichester, UK

Gelman, S., Mannheim, B., Escalante, C., \& Sanchez Tapia, I. (2015). Teleological talk in parentchild conversations in Quechua. First Language, 35.

Greenfield, P. M. (2010). Linking social change and developmental change: Shifting pathways of human development. Developmental Psychology, 45, 401-418.

Heinrich, J., Heins, S. J., \& Norenzayan, A. (2010). The weirdest people in the world? Behavioral \& Brain Sciences, 33, 61-83.

Keller, H. (2012). Autonomy and relatedness revisited: Cultural manifestations of universal human needs. Child Development Perspectives, 6, 12-18.

Kelly, B. F., Forshaw, W., Nordlinger, R., \& Wigglesworth, G. (2015). Linguistic diversity in first language acquisition research: Moving beyond the challenges. First Language, 35, 286-304.

Lebon-Eyquem, M. (2015). Specific linguistic profiles in a Creole-speaking area: Children's speech on Reunion Island. First Language, 35, 327-340.

Lieven, E., \& Stoll, S. (2010). Language. In M. Bornstein (Ed.), The handbook of cross-cultural developmental science (pp. 143-160). Mahwah, NJ: Lawrence Erlbaum.

Lieven, E., \& Stoll, S. (2013). Early communicative development in two cultures: A comparison of the communicative environments of children from two cultures. Human Development, 56, 178-206.

MacWhinney, B., \& Bates, E. (1989). The crosslinguistic study of sentence processing. Cambridge, UK: Cambridge University Press.

Ochs, E. (1982). Talking to children in Western Samoa. Language in Society, 11, 77-104. 
O’Shannessy, C. (2015). Multilingual children increase language differentiation by indexing communities of practice. First Language, 35, 305-326.

Reese, E., Ballard, E., Taumoepeau, M., Taumoefolau, M., Morton, S. B., Grant, C., \& Perese, L. (2015). Estimating language skills in Samoan- and Tongan-speaking children growing up in New Zealand. First Language, 35, 407-427.

Slobin, D. I. (1985). Crosslinguistic evidence for the language-making capacity. In D. I. Slobin (Ed.), The crosslinguistic study of language acquisition, vol. 2: Theoretical issues (pp. 11571256). Hillsdale, NJ: Lawrence Erlbaum.

Slobin, D. I. (1985-1997). The crosslinguistic study of language acquisition (Vols. 1-5). Hillsdale, NJ: Lawrence Erlbaum.

Stoll, S., Zakharko, T., Moran, S., Schikowski, R., \& Bickel, B. (2015). Syntactic mixing across generations in an environment of community-wide bilingualism. Frontiers in Psychology, 6, 82.

Vogt, P., Schots, D., \& Mastin, J. D. (2015). Communicative intentions of child-directed speech in three different learning environments: Observations from the Netherlands, and rural and urban Mozambique. First Language, 35, 341-358. 